\title{
Effect of Insulin on the Distribution of Cardiac Output in the Fetal Lamb
}

\author{
J. ROSS MILLEY \\ Division of Neonatology, Department of Pediatrics, Magee-Womens Hospital, University of Pittsburgh School of \\ Medicine, Pittsburgh, Pennsylvania 15213
}

\begin{abstract}
Three to five measurements of fetal cardiac output and its distribution were made using radiolabeled microspheres in each of 12 sheep fetuses in whom fetal plasma insulin concentration was varied by exogenous infusion of insulin to the fetus. Blood concentrations of oxygen and glucose as well as blood gases, $\mathrm{pH}$, hematocrit, and plasma insulin concentrations were also measured. Both fetal arterial oxygen content and whole blood glucose concentration fell as fetal insulin concentration rose. Fetal cardiac output rose as insulin concentration increased and was accompanied by an increase in fetal heart rate. Increased insulin concentration was associated with increased flow to the heart, stomach, placenta, and carcass while blood flow to the fetal brain, lungs, liver, kidneys, spleen, and intestines was not affected. As plasma insulin concentration rose, the percentage of the cardiac output distributed to the fetal heart and upper carcass increased; that distributed to the fetal brain, lungs, liver, stomach, intestines, and lower carcass remained unchanged; while that distributed to the kidneys, spleen, and placenta decreased. When expressed as a fraction of cardiac output, an additional $7 \%$ (from 39 to $46 \%$ ) of the cardiac output was distributed to carcass over the range of insulin concentrations studied. Most of the increased portion of the fetal cardiac output distributed to the fetal carcass during hyperinsulinemia was accounted for by a decrease in the percentage of fetal cardiac output perfusing the placenta. (Pediatr Res 22: 168-172, 1987)
\end{abstract}

Insulin has an important role in the regulation of near term fetal growth and metabolism. During hyperinsulinemia in the near term sheep fetus, metabolic rate rises without a corresponding increase in oxygen delivery and, consequently, fetal arterial oxygen content falls (1). Changes in arterial oxygen content have been shown to have important effects on the distribution of blood flow to the various fetal organs (2). Insulin itself has been shown to have significant effects on both cardiac output and regional blood flows in adult dogs (3). Also, the combination of fetal hyperinsulinemia and hyperglycemia caused by maternal glucose infusion causes a redistribution of fetal cardiac output with decreased placental flow and increased flow to the fetal carcass, heart, intestines, kidney, liver, and adrenals (4). Hyperinsulinemic hypoglycemia has been shown to alter one regional flow, the cerebral circulation, in the near term sheep fetus (5). However, no single experiment has examined changes in cardiac output and its distribution during direct fetal insulin infusion.

Received October 9, 1986; accepted March 2, 1987

Correspondence and reprints to J. Ross Milley, M.D., Ph.D., Department of Pediatrics, Magee-Womens Hospital, Forbes Avenue and Halket Street, Pittsburgh, PA 15213 .

Supported by a grant from the Children's Hospital of Pittsburgh.
This study, therefore, was designed to measure the effect of changes of plasma insulin concentration induced by exogenous infusion of insulin to the sheep fetus on the magnitude and distribution of fetal cardiac output.

\section{MATERIALS AND METHODS}

Twelve ewes were used whose gestational age ranged from $115-123$ days $($ mean $=120$ days or $82 \%$ of term). All had singleton pregnancies except one ewe who carried twin fetuses one of which was used for the experiment. The ewe was anesthetized with an epidural or spinal anesthetic (tetracaine hydrochloride, $1 \%$ ), a midline incision was made in the ewe's abdomen, the pregnant uterus was exposed, and a hysterotomy performed over the region of the fetal neck. After the fetal neck was infiltrated locally with lidocaine hydrochloride $(0.5 \%)$, an incision was made, and a catheter placed through one carotid artery into the brachiocephalic artery. As this uterine incision was closed, a catheter was placed in the amniotic sac. Through a second uterine incision, two fetal aortic catheters were placed via both hind limb arteries and a fetal inferior vena caval catheter was placed via a hind limb vein. In some animals, an umbilical venous catheter was placed for studies not included herein. The hysterotomy and maternal abdominal incisions were then closed and all catheters were tunnelled subcutaneously to the ewe's flank, where they were stored in a canvas pouch until needed. The ewe was allowed free access to food and water for 5 days after the operation. To accustom her to the experimental conditions, she was placed daily in the cart used for the experiment. Heparin $(100 \mathrm{U} / \mathrm{ml})$ was kept in the catheters to ensure patency.

Infusion. On the 5 th postoperative day, an infusion was begun at a rate of $1 \mathrm{ml} / \mathrm{h}$ into the fetal venous catheter using a precalibrated pump (Model 341A, Sage Instruments, Cambridge, MA). Each infusate contained either $0.9 \%$ saline or pork insulin (U-100, Eli Lilly and Co., Indianapolis, IN) in $0.9 \%$ saline at a randomly selected concentration (up to $120 \mathrm{mU} / \mathrm{ml}$ ). It has previously been shown that the insulin concentration of the infusate remained constant over the course of the infusion (1).

Experiment. After $18 \mathrm{~h}$ of infusion, $30 \mathrm{ml}$ of arterial blood was drawn from the fetal descending aorta for the analysis of oxygen content, blood glucose concentration, fetal blood gases, $\mathrm{pH}$, hematocrit, and plasma insulin concentration. Once blood sampling was finished, 1 to $2 \times 10^{6}$ microspheres $(15 \mu$ diameter; labeled with scandium 46 , chromium 51 , strontium 85 , niobium 95 , iodine 125 , or cerium 141) were injected over $20 \mathrm{~s}$ into the fetal inferior vena cava to measure blood flows $(6)$ to the various organs. The technique used relied on a reference arterial flow measurement (7). Reference samples of blood were drawn simultaneously from the fetal descending aorta and brachiocephalic artery at a rate of $4 \mathrm{ml} / \mathrm{min}$, beginning $10 \mathrm{~s}$ before and continuing for $60 \mathrm{~s}$ after the completion of the microsphere injection. During the blood sampling and injection procedures, fetal heart rate and arterial blood pressure were measured using 
Statham P23Db pressure transducers and recorded on a multichannel recorder (Model R611A, Beckman Instruments, Inc. Palo Alto, CA). Pressure measurements were calibrated against a standard mercury manometer and used intraamniotic pressure (measured through the amniotic catheter) as a reference zero pressure.

Six hours later a new insulin infusate concentration was selected and used over the next 18 -h infusion period. Three to five different insulin concentrations were infused into each fetus and a different microsphere injection was used to measure blood flows after blood samples were taken at each insulin concentration. At the end of the experiment, the ewe was killed with a rapid intravenous infusion of euthansia solution. The position of all catheters was verified during the fetal autopsy. The fetus was divided into its component organs and, after each organ was weighed, was incinerated at $280^{\circ} \mathrm{C}$ for 48 to $72 \mathrm{~h}$. The ashed tissues were then packed into vials. The radioactivity in the various fetal organs, the placenta, and the reference blood samples was measured in a well-type $\gamma$ scintillation counter (Model 1185R, Searle Analytical, Des Plaines, IL) equipped with a 1024channel pulse height analyzer (Ultima II, Norland Instruments, Ft. Atkinson, WI). Separation of nuclide counts was performed by computer (8). Both placenta and reference arterial blood samples contained more than 1500 microspheres to ensure that the error in blood flow measurement was less than $5 \%$ at the $95 \%$ confidence limits (9). In all, 19 infusions were completed with an insulin concentration of 0 , while 25 other infusions ranged in concentration from 1.3 to $41.3 \mathrm{mU} / \mathrm{kg} / \mathrm{h}$ based on the weight of the fetus at autopsy.

Analyses. Arterial $\mathrm{pH}, \mathrm{pO}_{2}$, and $\mathrm{pCO}_{2}$ were measured with a pH/Blood Gas Analyzer (Model 168, Corning Medical, Medfield, MA). Hematocrit was measured by the microhematocrit method. Blood samples for measurement of $\mathrm{O}_{2}$ content were kept anaerobically at $0^{\circ} \mathrm{C}$ until analysis. The measurements were made in duplicate on a Lex- $\mathrm{O}_{2}$-Con oxygen analyzer (Lexington Instruments Corp., Waltham, MA). Whole blood glucose was measured by a modified glucose oxidase method. Plasma insulin concentrations were measured using a modification (10) of a double antibody separation technique (11) standardized against ovine insulin (provided by Dr. M. A. Root, Eli Lilly Laboratories, Indianapolis, IN).

Calculations. Organ blood flow was calculated as:

$$
\mathrm{Q}_{\text {org }}=\left[\mathrm{cpm}_{\text {org }} / \mathrm{cpm}_{\text {ref }}\right] \times \mathrm{Q}_{\text {ref }}
$$

where $\mathrm{cpm}_{\text {org }}$ was the radioactive $\mathrm{cpm}$ in a given organ, $\mathrm{cpm}_{\text {ref }}$ was the radioactive $\mathrm{cpm}$ in the reference brachiocephalic arterial or aortic blood sample, and $\mathrm{Q}_{\text {ref }}$ was the reference blood flow (reference syringe withdrawal rate). The brachiocephalic artery reference was used for the calculation of flow to the brain, heart, lungs, and the fetal carcass above the seventh intercostal space. The descending aortic reference catheter was used to calculate blood flows to the liver (hepatic arterial circulation only), other abdominal organs, placenta, and the fetal carcass below the seventh intercostal space. The fetal cardiac output was the sum of the organ blood flows.

To reduce interanimal variability and to present the data in the most conventional form, the data were normalized to the fetal weight measured at the end of the experiment. Any bias that might have been introduced because of increases in organ or fetal weight would be related to advancing fetal age and, therefore, to the duration of the experiment. Since this experiment was designed to eliminate these latter sources of possible bias, variation due to advancing gestational age (or fetal weight) would not affect the variation we have attributed to the effects of fetal plasma insulin concentration.

Statistics. Relationships that contained the duration of the experiment as the independent variable were defined by analysis of covariance. Since changes in fetal hematocrit affect fetal blood flow (12) and might obscure the effects of changes in insulin concentration, multiple regression covariance analysis (13) was used with both insulin concentration and hematocrit as independent variables to define which independent variable was responsible for the changes measured in the dependent variables (1). The null hypothesis that the regression coefficient was zero (i.e. there was no relation between insulin concentration and a given dependent variable) was disproved by testing against the $t$ distribution. Since the relation to insulin concentration of the dependent variables measured in this study was sometimes obscured by variations between animals or as a result of changes in hematocrit, the data points presented in the accompanying figures have all been corrected, as previously described (1), to the mean experimental hematocrit and the portion of the variation due to interanimal variability has been subtracted from each data point. All results are expressed as the mean \pm SEM.

\section{RESULTS}

A total of 44 studies was completed in 12 animals. Fetal pH and arterial blood gases were within normal limits during all of the experiments and did not change as the experiment progressed. Fetal hematocrit, which was initially normal at $32.2 \pm$ $1.5 \%$, fell, due to blood sampling, by $1.3 \pm 0.3 \%$ each day that the experiment progressed so that in the animals studied on 5 consecutive days, the day 5 hematocrit was $27.3 \pm 3.9 \%$. Because insulin infusion rates were varied so that lower insulin concentrations occurred predominately on study days 1,3 , and 5 while higher concentrations occurred on days 2,3 , and 4 , the experiment was balanced so that neither the concentration of insulin in the infusate nor the fetal plasma insulin concentration was related to the duration of the experiment. Consequently, neither variable was related to hematocrit. Fetal plasma insulin concentrations ranged from 0.3 to $60.8 \mu \mathrm{U} / \mathrm{ml}$ during this experiment.

During the control infusions (19 infusions containing no insulin), the mean fetal plasma insulin concentration was $4.9 \pm$ $1.0 \mu \mathrm{U} / \mathrm{ml}$ and the arterial concentrations of both oxygen $(2.45$ $\pm 0.11 \mathrm{mM})$ and glucose $(0.947 \pm 0.051 \mathrm{mM})$ were normal. As insulin concentration rose, fetal arterial concentrations of both these substances fell. Specifically, fetal arterial oxygen content fell by $0.0045 \pm 0.0021 \mathrm{mmol} /$ liter $(n=43, p=0.039)$ for each $\mu \mathrm{U} / \mathrm{ml}$ fall of fetal insulin concentration while fetal arterial blood glucose concentration fell by $0.0099 \pm 0.0010 \mathrm{mmol} /$ liter $(n=$ $38, p<0.0001$ ) for each $\mu \mathrm{U} / \mathrm{ml}$ fall of insulin concentration

During control infusions fetal cardiac output was $484 \pm 18$ $\mathrm{ml} / \mathrm{kg} / \mathrm{min}$. Figure $1 A$ shows that cardiac output rose as insulin concentration increased. Fetal heart rate, which was $177 \pm 4$ beats/min when the infusate contained no insulin, also rose (Fig. $1 B)$ as insulin concentration rose. There was no effect of insulin concentration of fetal blood pressure. The mean blood pressure during all 44 infusions was $48 \pm 1 \mathrm{~mm} \mathrm{Hg}$.

Fetal organ blood flows are shown in Table 1. A rise in insulin concentration was associated with increased flow to the heart, stomach, placenta (umbilical circulation), and carcass (both upper and lower body). There was no relationship between fetal plasma insulin concentration and blood flow to the brain, lungs, liver (via the hepatic artery), right kidney, left kidney, spleen, and intestines. Since blood flow increased to both upper and lower carcass as insulin concentration rose, flow to the entire carcass (Fig. $2 A$ ) increased as well

Fetal organ blood flows are shown as a percentage of cardiac output in Table 2 . The percentage of the cardiac output distributed to the heart and upper carcass increased as plasma insulin concentration rose. There was no relationship between plasma insulin concentration and the percentage of cardiac output to the fetal brain, lungs, liver (via hepatic artery), stomach, intestines, or lower carcass. The right and left kidneys, spleen, and placenta (via the umbilical circulation) received a smaller proportion of the fetal cardiac output as insulin concentration rose. Although the lower carcass did not receive an increasing proportion of cardiac output as insulin concentration rose, the relation approached significance. Consequently, there was a significant 
increase in the proportion of total cardiac output to the entire fetal carcass related to fetal plasma insulin concentration (Fig. $2 B)$.

\section{DISCUSSION}

This experiment showed increased blood flow to fetal carcass, heart, stomach, and placenta during exogenously induced fetal hyperinsulinemia. Fetal cardiac output also increased with a

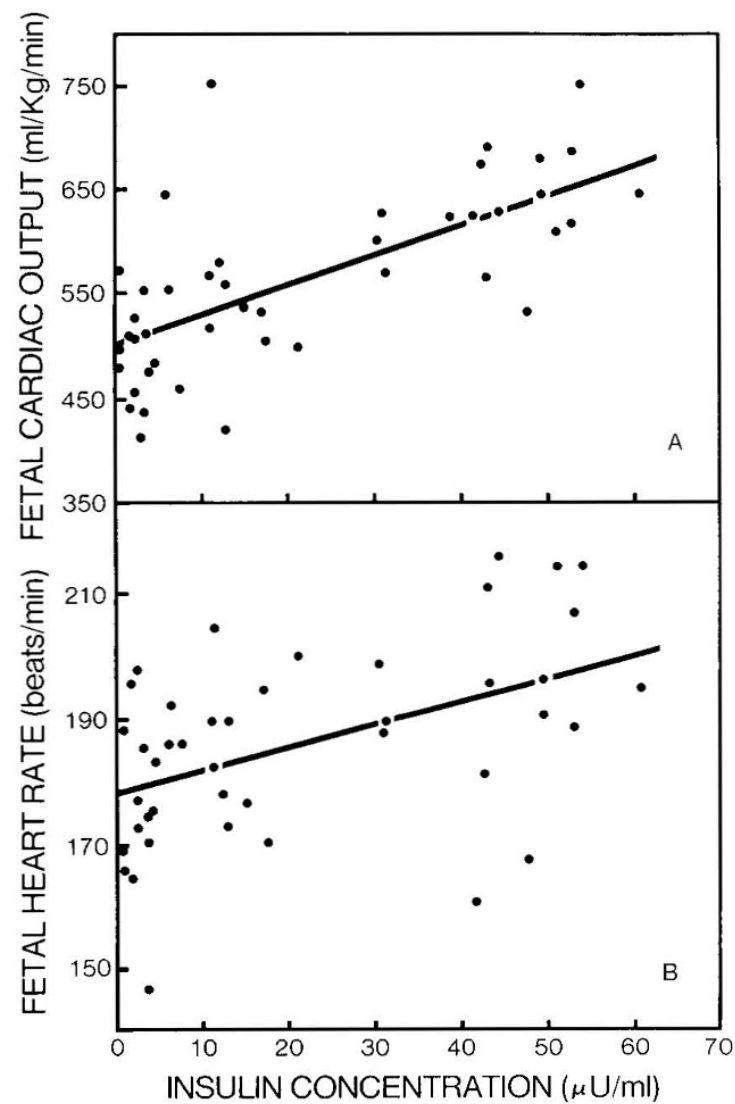

Fig. 1. Fetal cardiac output and heart rate as a function of fetal plasma insulin concentration. The data points have been corrected as described in "Materials and Methods." $A$, fetal cardiac output $=2.79$ (insulin concentration) $+501 ; \mathrm{SE}$ slope $=0.57 ; n=44 ; p<0.0001 . B$, fetal heart rate $=0.35$ (insulin concentration) $+179 ;$ SE slope $=0.13 ; n$ $=43 ; p=0.0093$. greater fraction distributed to fetal carcass and heart and a lesser fraction distributed to the placenta. Before further discussion, however, several issues related to experimental design need to be addressed. First, insulin infusion rates which resulted in plasma insulin concentrations less than $100 \mu \mathrm{U} / \mathrm{ml}$ were used. This range was chosen because it is the range of endogenous plasma insulin concentrations that occur when the ovine fetal pancreas is stimulated by fetal glucose infusion (14). Second, because fetal blood was sampled during the experiment, an unavoidable fall in fetal hematocrit occurred. So that this fall in hematocrit would

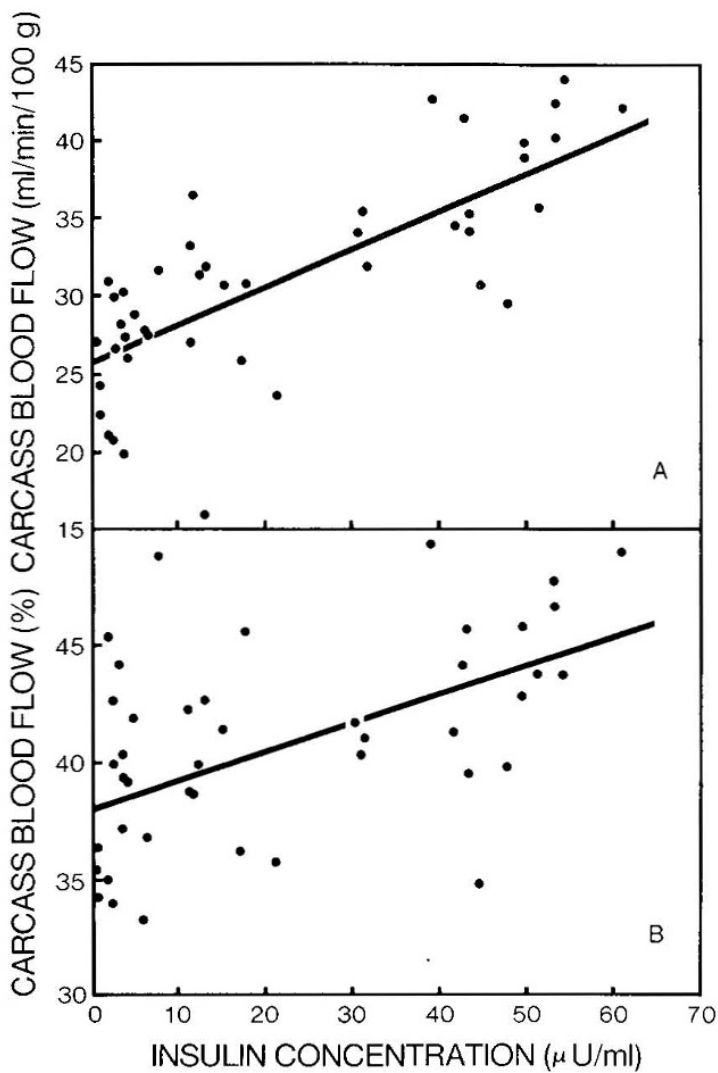

Fig. 2. The relation of carcass blood flow to fetal plasma insulin concentration. The data points shown have been corrected as described in methods. $A$, carcass blood flow $-\mathrm{ml} / \mathrm{min} / 100 \mathrm{~g}$ tissue $=0.244$ (insulin concentration) +26 ; SE slope $=0.040 ; n=44 ; p<0.0001$. $B$, carcass blood flow - percent of cardiac output $=0.120$ (insulin concentration) $+38 ;$ SE slope $=0.037 ; n=44 ; p=0.0023$.

Table 1. Relationships of fetal organ blood flows to fetal plasma insulin concentration

\begin{tabular}{|c|c|c|c|c|c|c|c|c|}
\hline \multicolumn{6}{|c|}{ Relationship } & \multirow[b]{2}{*}{ SE slope } & \multirow[b]{2}{*}{$p$} & \multirow{2}{*}{$\begin{array}{c}\text { Organ blood flow } \\
\text { during saline infusion } \\
n=19 \\
(\mathrm{ml} / \mathrm{min} / 100 \mathrm{~g})\end{array}$} \\
\hline $\begin{array}{l}\text { Organ blood flow } \\
(\mathrm{ml} / \mathrm{min} / 100 \mathrm{~g})\end{array}$ & $=$ & intercept* & + & slope & $\times \underset{(\mu \mathrm{U} / \mathrm{ml})}{[\mathrm{Ins}]}$ & & & \\
\hline Heart & $=$ & 207 & + & 2.78 & ([Ins]) & 0.58 & $<0.0001$ & $189 \pm 14$ \\
\hline Brain & $=$ & 157 & + & 0.57 & ([Ins]) & 0.33 & 0.090 & $149 \pm 10$ \\
\hline Lung & $=$ & 129 & - & 0.18 & ([Ins]) & 0.99 & 0.86 & $78 \pm 11$ \\
\hline Upper carcass & $=$ & 26 & + & 0.29 & ([Ins]) & 0.05 & $<0.0001$ & $26 \pm 1$ \\
\hline Stomach & $=$ & 57 & + & 0.38 & ([Ins]) & 0.12 & 0.0027 & $56 \pm 4$ \\
\hline Intestine & $=$ & 160 & + & 0.53 & ([Ins]) & 0.29 & 0.077 & $152 \pm 8$ \\
\hline Liver & $=$ & 13 & + & 0.03 & ([Ins]) & 0.08 & 0.70 & $13 \pm 3$ \\
\hline Right kidney & $=$ & 201 & + & 0.44 & ([Ins]) & 0.43 & 0.31 & $196 \pm 13$ \\
\hline Left kidney & $=$ & 204 & + & 0.22 & ([Ins]) & 0.38 & 0.56 & $197 \pm 13$ \\
\hline Spleen & $=$ & 397 & - & 0.37 & ([Ins]) & 1.06 & 0.73 & $364 \pm 40$ \\
\hline Lower carcass & $=$ & 26 & + & 0.20 & ([Ins]) & 0.04 & $<0.0001$ & $26 \pm 1$ \\
\hline Placenta & $=$ & 232 & + & 0.70 & ([Ins]) & 0.28 & 0.018 & $212 \pm 34$ \\
\hline
\end{tabular}

* The intercept was calculated from the mean blood flow, insulin concentration, and hematocrit for each relationship. 
INSULIN AND FETAL CARDIAC OUTPUT

Table 2. Relationship of fetal cardiac output distribution to fetal plasma insulin concentration

\begin{tabular}{|c|c|c|c|c|c|c|c|c|}
\hline \multicolumn{6}{|c|}{ Relationship } & \multirow[b]{2}{*}{ SE slope } & \multirow[b]{2}{*}{$p$} & \multirow{2}{*}{$\begin{array}{c}\text { Organ blood flow } \\
\text { during saline infusion } \\
n=19 \\
\text { (\% cardiac output) }\end{array}$} \\
\hline $\begin{array}{l}\text { Organ blood flow } \\
\text { (\% cardiac output) }\end{array}$ & $=$ & intercept* & + & slope & $\times \underset{(\mu \mathrm{U} / \mathrm{ml})}{[\mathrm{Ins}]}$ & & & \\
\hline Heart & $=$ & 3.09 & + & 0.0184 & $([\operatorname{Ins}])$ & 0.0066 & 0.0078 & $2.91 \pm 0.22$ \\
\hline Brain & $=$ & 4.76 & - & 0.0093 & ([Ins]) & 0.0078 & 0.24 & $4.62 \pm 0.26$ \\
\hline Lung & $=$ & 6.96 & - & 0.017 & ([Ins]) & 0.0037 & 0.65 & $5.25 \pm 0.66$ \\
\hline Upper carcass & $=$ & 19.32 & + & 0.086 & ([Ins]) & 0.026 & 0.0023 & $19.96 \pm 0.97$ \\
\hline Stomach & $=$ & 1.01 & - & 0.0006 & ([Ins]) & 0.0015 & 0.72 & $0.98 \pm 0.06$ \\
\hline Intestine & $=$ & 4.82 & - & 0.0128 & ([Ins]) & 0.0068 & 0.067 & $4.75 \pm 0.36$ \\
\hline Liver & $=$ & 0.81 & - & 0.0015 & ([Ins]) & 0.0045 & 0.74 & $0.77 \pm 0.11$ \\
\hline Right kidney & $=$ & 1.21 & - & 0.0044 & ([Ins]) & 0.0018 & 0.020 & $1.20 \pm 0.07$ \\
\hline Left kidney & $=$ & 1.23 & - & 0.0050 & ([Ins]) & 0.0016 & 0.0036 & $1.22 \pm 0.07$ \\
\hline Spleen & $=$ & 1.64 & - & 0.0074 & ([Ins]) & 0.0035 & 0.043 & $1.59 \pm 0.16$ \\
\hline Lower carcass & $=$ & 18.82 & + & 0.0034 & ([Ins]) & 0.018 & 0.073 & $19.09 \pm 0.50$ \\
\hline Placenta & $=$ & 36.37 & - & 0.083 & ([Ins]) & 0.036 & 0.024 & $37.61 \pm 1.42$ \\
\hline
\end{tabular}

* The intercept was calculated from the mean percentage of cardiac output, insulin concentration, and hematocrit for each relationship.

not bias the results, the experiment was designed so that neither the duration of the experiment nor hematocrit were related to plasma insulin concentrations. Third, the effects of insulin on fetal metabolism caused the arterial concentration of both oxygen and glucose to fall. In other studies of fetal hyperinsulinemia, the blood concentrations of other metabolic substrates such as lactate and amino-nitrogen also fall (1) and the plasma concentrations of hormones such as growth hormone and ACTH increase (15). Changes in variables such as these are generally unavoidable covariates with changes in insulin concentration during in vivo experiments.

Blood flow to fetal carcass, which includes muscle, bone, connective tissues, fat, and skin, increased as insulin concentration rose. This increase occurred whether the tissues were supplied from the ascending or descending aorta. The increase in tissue blood flow expected over the $60 \mu \mathrm{U} / \mathrm{ml}$ range of insulin concentrations studied in this experiment was $14.6 \mathrm{ml} / 100 \mathrm{~g} /$ min or an increase in carcass blood flow to $156 \%$ of control. When expressed as a fraction of cardiac output, an additional $7 \%$ (from 39 to $46 \%$ ) of the cardiac output would be distributed to carcass over the range of insulin concentrations studied. Increased carcass blood flow has not been reported in response to other disturbances of fetal homeostasis which increase sympathetic stimulation (16-18) suggesting that the effects of fetal hyperinsulinemia on carcass blood flow may be independent of sympathetic stimulation. Under other conditions, muscle blood flow, one component of carcass, is tightly coupled to tissue metabolic rate (19). Preliminary evidence suggests that insulin increases the metabolic rate of fetal carcass tissues (20). Therefore, it is tempting to postulate that increased fetal carcass blood flow during hyperinsulinemia occurs because blood flow is coupled to increased carcass metabolic rate.

During infusions of normal saline into the fetus, fetal cardiac output was normal $(2,12,16,17)$. As plasma insulin concentration increased, fetal cardiac output rose by $167 \mathrm{ml} / \mathrm{kg} / \mathrm{min}$ (to $134 \%$ of control) over the $60 \mu \mathrm{U} / \mathrm{ml}$ range of insulin concentrations found in the present experiment. Such an increase in cardiac output would be expected as peripheral resistance decreases (i.e. carcass blood flow increases at constant blood pressure) and the effects of insulin in cardiac output would therefore be due to the effects of insulin on carcass blood flow. An alternative explanation is suggested by studies in adult dogs which have shown that increases in cardiac output associated with insulin infusion may be mediated by catecholamines $(3,21)$. However, in contrast to postnatal life, neither direct infusion of catecholamines (17) nor agents that block their action (18) alter cardiac output in the ovine fetus. Therefore, the effects of increased catecholamine concentrations on fetal cardiac output differ from those of increased insulin concentration, and it is unlikely that the effects of insulin on fetal cardiac output are consequent to effects on catecholamine concentrations.

Fetal heart rate increased as a function of insulin concentration so that, over a $60 \mu \mathrm{U} / \mathrm{ml}$ range of insulin concentrations, heart rate would be expected to rise by 21 beats/min to $112 \%$ of control measurements. Fetal blood pressure, which was normal during the experiments, was not related to plasma insulin concentration. At least part, if not all, of the increase in cardiac output was probably due to the increase noted in fetal heart rate. When fetal hyperinsulinemia is secondary to maternal glucose infusion, fetal heart rate has been reported to decrease rather than increase (4). However, not only fetal hyperglycemia but also fetal acidosis and lactate accumulation occurred during this latter experiment and these variables may have had independent effects on fetal heart rate.

Myocardial blood flow, expressed either in terms of tissue flow or as a percentage of cardiac output, increased as insulin concentration rose. A similar finding (4) during fetal hyperinsulinism caused by maternal glucose infusion and associated with fetal hyperglycemia suggests that this effect of insulin is independent of fetal glucose concentration. This increase in blood flow occurs when cardiac work (i.e. cardiac output), and presumably myocardial metabolic needs, are increasing. Further experiments will be needed to show if the increase in myocardial blood flow found in these hyperinsulinemic fetuses is mediated by cardiac $\beta$ adrenergic stimulation, increased cardiac metabolic needs during increased work, or some other type of vasomotor regulation.

Blood flow to the placenta through the umbilical circulation increased as a function of fetal insulin concentration. Decreased $(4,22)$ and unchanged umbilical flows $(23,24)$ have also been reported in relation to fetal insulin concentrations. However, during these other experiments, the effects of hematocrit and the order in which flow measurements were made were not controlled and may have biased the findings. Umbilical blood flow to the placenta decreased as insulin concentration increased when expressed as a proportion of the cardiac output rather than as flow per unit tissue weight. Over the range of insulin concentrations studied, the regression equation would predict a $5 \%$ fall in the portion of the fetal cardiac output perfusing the placenta. This fall in placental perfusion by the fetus accounts for most of the predicted $7 \%$ increase in cardiac output distributed to carcass over the same range of insulin concentrations.

The percentage of cardiac output distributed to several other organs, specifically spleen and kidneys (and possibly also the intestines, although this latter effect did not reach significance) fell as insulin concentration increased. Cerebral blood flow, however, appeared unaffected by fetal hyperinsulinemia whether, as in this experiment, exogenously produced, or as previously reported (4), induced endogenously. Because cerebral blood flow 
is tightly coupled to cerebral metabolic rate (25), this lack of change in cerebral blood flow suggests, although direct measurements are lacking, an independence of cerebral metabolic rate and fetal insulin concentration. In contrast, Richardson et al. (5) report decreased cerebral blood flow and decreased cerebral metabolic rate during exogenous hyperinsulinemia in fetal lambs. Their studies were done at much higher insulin infusion rates and more acutely ( $2-4 \mathrm{~h}$ of infusion) than the present experiments, however, and thus are not directly comparable.

In summary, fetal hyperinsulinemia alters the magnitude and distribution of fetal cardiac output. Carcass comprises a sufficient portion of the fetal cardiac output so that the increased need for blood flow to these tissues explains the need for increased cardiac output. The need for increased cardiac output is met by increasing fetal heart rate. Because placental perfusion does not increase as rapidly as the perfusion of the carcass, the placental receives a smaller proportion of the fetal cardiac output.

\section{REFERENCES}

1. Milley JR, Papacostas JS, Tabata BK 1986 Effect of insulin on the uptake of metabolic substrates by the ovine fetus. Am J Physiol 251(Endocrinol Metab 14):E349-E356

2. Peeters LLH, Sheldon RE, Jones MD Jr, Makowski EL, Meschia G 1979 Blood flow to fetal organs as a function of arterial oxygen content. Am J Obstet Gynecol 135:637-646

3. Liang C, Doherty JU, Faillace R, Maekawa K, Arnold S, Gavras H, Hood WB 1982 Insulin infusion in conscious dogs: effects on systemic and coronary hemodynamics, regional blood flows, and plasma catecholamines. $\mathbf{J}$ Clin Invest 69:1321-1336

4. Crandell SS, Fisher DJ, Morriss FH Jr 1985 Effects of ovine maternal hyperglycemia on fetal regional blood flows and metabolism. Am J Physio 249(Endocrinol Metab 12):E454-E460

5. Richardson BS, Hohimer AR, Bissonette JM, Machida CM 1985 Insulin hypoglycemia, cerebral metabolism, and neural function in fetal lambs. Am J Physiol 248(Regulatory Integrative Comp Physiol 17):R72-R77

6. Rudolph AM, Heymann MA 1967 The circulation of the fetus in utero. Methods for studying distribution of blood flow, cardiac output and organ blood flow. Circ Res 21:163-184

7. Makowski EL, Meschia G, Droegemueller W, Battaglia FC 1968 Measurement of umbilical arterial blood flow to the sheep placenta and fetus in utero. Circ Res 23:623-631

8. Baer RW, Payne BD, Verrier ED, Vlahakes GJ, Molodowitch D, Uhlig PN,
Hoffman JIE 1984 Increased number of myocardial blood flow measurements with radionucleotide-labelled microspheres. Am J Physiol 246(Heart Circ Physiol 5):H418-H434

9. Buckberg GD, Luck JC, Payne BD, Hoffman JIE, Archie JP, Fixler DE 1971 Some sources of error in measuring regional blood flow with radioactive microspheres. J Appl Physiol 31:598-604

10. Philipps AF, Carson BS, Meschia G, Battaglia FC 1978 Insulin secretion in fetal and newborn sheep. Am J Physiol 235(Endocrinol Metab Gastrointestinal Physiol 4):E467-E474

11. Morgan CR, Lazarow A 1963 Immunoassay of insulin: two antibody systems. Diabetes 12:115-126

12. Fumia FD, Edelstone DI, Holzman IR 1984 Blood flow and oxygen delivery to fetal organs as functions of fetal hematocrit. Am J Obstet Gynecol 150:274-282

13. Snedecor GW, Cochran WG 1967 Statistical Methods. The Iowa State University Press, Ames, IA, pp 419-446

14. Philipps AF, Porte PJ, Stabinsky S, Rosenkrantz TS, Raye JR 1984 Effects of chronic hyperglycemia upon oxygen consumption in the ovine uterus and conceptus. J Clin Invest 74:279-286

15. Spenser GSG, Garssen GJ Colenbrander B, MacDonald AA, Bevers MM 1983 Glucose, growth hormone, somatomedin, cortisol and ACTH changes in the plasma of unanesthetized pig foetuses following intravenous insulin administration in utero. Acta Endocrinol 104:240-245

16. Cohn HE, Sacks EJ, Heymann MA, Rudolph AM 1974 Cardiovascular responses to hypoxemia and acidemia in fetal lambs. Am J Obstet Gynecol 120:817-824

17. Lorijn RHW, Longo LD 1980 Norepinephrine elevation in the fetal lamb: oxygen consumption and cardiac output. Am J Physiol 239(Regulatory Integrative Comp Physiol 8):R115-R122

18. Barrett CT, Heymann MA, Rudolph AM 1972 Alpha and beta receptor activity in fetal sheep. Am J Obstet Gynecol 112:1114-1121

19. Thompson LP, Mohrman DE 1983 Blood flow and oxygen consumption in skeletal muscle during sympathetic stimulation. Am J Physiol 245(Heart Circ Physiol 14):H66-H71

20. Milley JR, Papacostas JA 1986 Hindlimb metabolic rate during fetal hyperinsulinemia. Pediatr Res 20:192A

21. Hackel DB 1960 Effect of insulin on cardiac metabolism of intact normal dogs. Am J Physiol 199:1135-1138

22. Milley JR, Rosenberg AA, Philipps AF, Molteni RA, Jones MD Jr, Simmons MA 1984 The effect of insulin on ovine fetal oxygen extraction. Am J Obstet Gynecol 149:673-678

23. Simmons MA, Jones MD, Battaglia FC, Meschia G 1978 Insulin effect on fetal glucose utilization. Pediatr Res 12:90-92

24. Hay WW, Meznarich HK, Sparks JW, Battaglia FC, Meschia G 1985 Effect of insulin on glucose uptake in near-term fetal lambs. Proc Soc Exp Biol Med 178:557-564

25. Jones MD Jr, Traystman RJ 1984 Cerebral oxygenation of the fetus, newborn, and adult. Semin Perinatol 8:205-216 